\title{
Dragonfly (Odonata) Species Diversity in Different Land Use Patterns of Lowland Tropical Wet Zone, Colombo District of Sri Lanka
}

\author{
Kanthika W.A.L., Kuruppuarachchi K.A.J.M.", Dharmasena M.C.M. and Cooray M.G. \\ Department of Botany, The Open University of Sri Lanka, Sri Lanka \\ *kajmkuruppu@gmail.com
}

\begin{abstract}
Many species of Odonates inhabiting in agro-ecosystems, play a crucial role in controlling pest populations and can be considered as a pollution indicator. Damselflies are important biocontrol agents especially in the control of mosquito larvae. Individual Odonata species have a wide range of environmental tolerances, and are good indicators of ecosystem health, particularly for wetlands. Odonata are also known to be highly responsive to ecosystem conditions in relation to broad-scale factors such as climate and urbanization. Huge knowledge gap displays in ecology of Odonata species and this preliminary study would provide a considerable knowledge on formulating conservation strategies and ecosystem services of dragonflies. The ecological survey examined the Dragonfly \& Damselfly (Odonata) species diversity and habitat preference in different land use types at low country wet zone of Colombo district, Sri Lanka. Five (05) main land use patterns were selected as sub-urban land set up at Waga Area: a natural forest (Indikada Mukalana), a rubber plantation, a paddy field as an agricultural land use; Urban land setup: The Open university premises (OUSL) at Nawala,Colombo and "Diyatha Uyana" Battaramulla. The ecological survey was carried out with layout of belt transect $(100 \mathrm{~m} \times 2.5)$ adjacent $(5-15 \mathrm{~m}$ distance) to selected water ways in each different sampling areas of different land use patterns which adapting purposive random sampling technique. Visual observations will be carried out adapting internationally accepted techniques for sampling of flying insects to identify and quantify of Dragonflies. Dragonfly and damselfly species specific parameters were recorded in selected sampling sites.Total number of 26 Odonata species including 09 endemics was recorded in all land using patterns all land use patterns. Species diversity (richness and abundance) measured within study sites using Shannon wiener index indicated that the paddy field (2.185), rubber plantation (1.885), natural forest (0.9507), OUSL along polluted Wellawatte canal (0.6745) and Diyatha Uyana (0.619) respectively. The number of dragonfly species and abundance is remarkably higher in urban sites while number of damselfly is higher in sub-urban paddy field and rubber plantation. Neurothemis tulia and Rhyothemis variegata species were recorded at all study sites except natural forest. Brachythemis contaminata is the most abundant species which is only recorded in urban sites. A considerable species diversity and variation of Odonata species among study sites were recognized. As a conclusive remark, further studies on find limiting factors for diversity, distribution and abundance of dragonfly \& damselfly species is recommended.
\end{abstract}

Keywords: Dragonfly diversity, Different land uses, Lowland wet zone, Colombo

Proceedings of the International Forestry and Environment Symposium 2016, Department of Forestry and Environmental Science, University of Sri Jayewardenepura, Sri Lanka. 